\title{
The use of the species concept in paleontology. Comment on "Nesiotites rafelinensis sp. nov., the earliest shrew (Mammalia, Soricidae) from the Balearic Islands, Spain" by Rofes et al., 2012
}

\author{
Marc Furió and Guillem Pons-Monjo
}

\begin{abstract}
The earliest representative of Nesiotites from Caló d'en Rafelino (Mallorca) has been recently described as a new species (Nesiotites rafelinensis) based on a single hemimandible with p4-m3. A thorough inspection of large collections of different species of Nesiotites from the Balearic Islands reveals wide intraspecific morphological variation within these Plio-Pleistocene shrews. Six out of seven diagnostic characters of $N$. rafelinensis fall within the variability of the oldest species previously known, $N$. ponsi. We thus conclude that no traits sufficiently support the definition of a new species, and in our opinion this material should be better referred to $N$. ponsi or to a closely related form ( $N$. aff. ponsi / N. cf. ponsi).
\end{abstract}

Marc Furió . Institut Català de Paleontologia M. Crusafont, Edifici ICP, Universitat Autònoma de Barcelona, Cerdanyola del Vallès, 08193, Barcelona, Spain. marc.furio@icp.cat

Guillem Pons-Monjo. Institut Català de Paleontologia M. Crusafont, Edifici ICP, Universitat Autònoma de Barcelona, Cerdanyola del Vallès, 08193, Barcelona, Spain. guillem.pons@icp.cat

Keywords: Lipotyphla; Nectogalini; Asoriculus; Mallorca; Nesiotites ponsi; biological variability

\section{INTRODUCTION}

Deciding which fossil specimens deserve the definition of a new species and which others do not, is not always an easy matter. Paleontologists-actually, all biologists-must consider a fact directly related with the very nature of evolution and natural selection before describing a fossil specimen as a new species: individual morphological variation exists in all monospecific populations.
That is, new species should not be erected based upon single specimens (especially if they are not complete), unless one or more diagnostic traits are completely out of the range of variation of all related species already known.

A good example to assess this issue is found in the recent work "Nesiotites rafelinensis sp. nov., the earliest shrew (Mammalia, Soricidae) from the Balearic Islands, Spain" by Rofes et al. (2012). In 


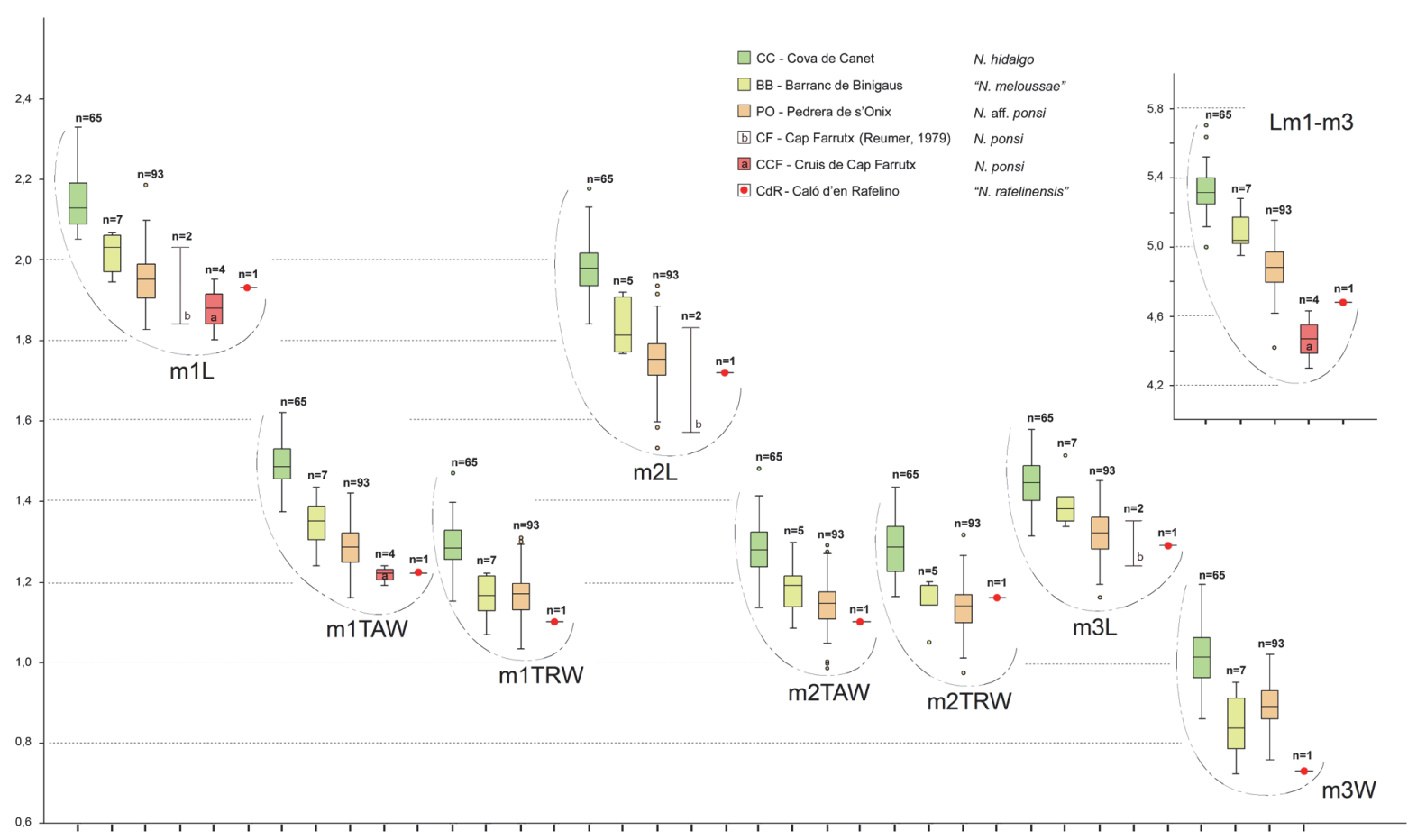

FIGURE 1. Boxplot comparing the measurements of Nesiotites from Caló d'en Rafelino with the other known fossil populations of the genus in the Balearic Islands. Notice that the only specimen of " $N$. rafelinensis" falls always within the variability range of $N$. ponsi from Cap Farrutx and/or $N$. aff. ponsi from Pedrera de s'Onix. Small circles represent outliers for each population (i.e., values exceeding between 1.5 and 3 times the box height above the top of the box or below its bottom). In the samples from Cap Farrutx with $n=2$, the box does not represent quartiles, but a total range according to maximum and minimum values provided by Reumer (1979).

our opinion, this is a nice descriptive and well-illustrated work on early fossil material of Nesiotites, the endemic insular genus of shrews that inhabited the Balearic Islands during the Pliocene and the Pleistocene. We regret, however, that the definition of this new species was only based upon one single specimen, a left mandibular fragment preserving only four teeth. Unluckily, it seems that we (i.e., both Rofes et al. and ourselves) have been carrying out complementary research unaware of each other's work. Our recent publication (Pons-Monjo et al., 2012), in which we studied more than 4,000 specimens of Nesiotites from the two main Balearic Islands, Mallorca and Menorca, focused on the interspecific and intraspecific variability of this genus. After our research, it has become evident that the genus Nesiotites displayed a high variability within all its populations. These results on the variability of three monospecific assemblages of Nesiotites from Pedrera de s'Ònix (PO), Cova de Canet (CC) and Barranc de Binigaus (BB) would certainly have benefitted Rofes and co-workers in assessing the taxonomic importance of different characters, had they known of this beforehand. As it is, the information from both papers became available simultaneously, and we can only compare the results in retrospect. In our opinion, the variation observed in the various assemblages of Nesiotites is wide enough to undermine the validity of the characters of $N$. rafelinensis as diagnostic for the definition of a new species.

\section{MATERIALS AND METHODS}

In the present attempt to assess the intraspecific variability on size and morphology within Balearic Nesiotites, we have extracted data from literature (Pons-Monjo et al., 2012; Reumer, 1979, 1980, 1984; Rofes et al., 2012), and obtained new information by personal reexamination, comparable to the holotype of $N$. rafelinensis (IMEDEA 91950; Rofes et al., 2012, figure 3). In the localities from Mallorca we measured all the left hemimandibles sufficiently clean and preserving the complete lower molar row (Pedrera de s'Onix, $n=93$; Cova de Canet, $n=65$ ). In Barranc de Binigaus (Menorca) we measured all (left and right) hemimandibles available preserving $\mathrm{m} 1$ and $\mathrm{m} 3$ because the sample was much smaller $(n=7)$. For morphological inspection, we employed all the comparable ele- 
ments available, either left or right. Figure 1 was performed using PAST 1.88 (Hammer et al., 2001). In the case of Cap Farrutx, the boxplots could not be generated because the samples were insufficient $(n=2)$. In these cases only the ranges were depicted, represented by two whiskers, minimal and maximal values. Photographs of Nesiotites mandibles in Figure 2 were taken with a Leica Binocular Stereoscope MZ 16 connected to a PC Computer with Leica Application Suite software. Both figures were later edited with Adobe Photoshop CS2 9.0.2 to improve their final quality.

\section{RESULTS AND DISCUSSION}

The diagnosis of $N$. rafelinensis details seven main characters (Rofes et al., 2012, p. 6): "1- Teeth dimensions close to N. ponsi, but mandibular body as large as in N. aff. ponsi from Pedrera de s'Ònix; 2- Not having accessory cusps on the oblique crest of $m 1$ and m2; 3- Cuspule and lingual crest on the posterolingual basin of p4 not as conspicuous as in N. ponsi, N. aff. ponsi or N. hidalgo; 4- Buccal and lingual cingula of the lower teeth comparatively broader and more pronounced than in any other species of Nesiotites; 5- Buccal cingulum of the lower molars (as in A. gibberodon) less undulated than in N. ponsi, N. aff. ponsi and N. hidalgo; 6Teeth stained a light orange at the top of the crowns (as in A. gibberodon); 7- Mental foramen slightly forward than in all other Nesiotites species." Below we present a thorough review of these seven characters, based on the work of Rofes et al. (2012) and new inspections on other fossil Balearic populations of Nesiotites.

With respect to tooth size, there are several objections. The first stems from figures 4 and 5 in Rofes et al. (2012). In figure 4, the bivariate diagram of the m1s L (length) and TAW (talonid width) shows that the $\mathrm{m} 1$ from Caló d'en Rafelino (CdR) is completely included in the $95 \%$ confidence ellipse of $N$. ponsi and also within $95 \%$ of $N$. aff. ponsi from $\mathrm{PO}$. Thus, this element is undistinguishable in size from $N$. ponsi. In figure 5, the PCA (PC1 vs PC2) also indicates that the specimen from CdR falls within the $95 \%$ confidence ellipse of both species (although not inside any convex hulls/ distribution). The logical deduction is that measurements are not enough to confidently discriminate this species from $N$. ponsi or $N$. aff. ponsi from $P O$.

As evidenced by the boxplot graph of Figure 1 , the specimen from CdR is always included in the variability range of $N$. ponsi, usually close to the median of this species. Nesiotites rafelinensis sometimes reaches values which could even corre- spond to $N$. aff. ponsi from PO. A last important objection with respect to the size is that the $m 3$ of the type specimen of $N$. rafelinensis is broken (Rofes et al., 2012, p. 6 and figure 3). Dimensions of Lm1-m3 and Lm3 of $N$. rafelinensis are therefore either not real or simply estimated, thus weakening the comparative analysis with other similar species.

The second diagnostic trait, the absence of accessory cusps in $\mathrm{m} 1$ and $\mathrm{m} 2$, is a very irregular character. Reumer (1979, p. 477) described this character as "often" present in N. ponsi. In our samples from BB, $\mathrm{PO}$ and $\mathrm{CC}$ we found that the presence of cuspules in the oblique cristid of $\mathrm{m} 1$ and $\mathrm{m} 2$ varies from $53.21 \%$ to $83.33 \%$ of the cases, being always more frequently present in $\mathrm{m} 1$ than in $\mathrm{m} 2$ within the same fossil assemblage (Pons-Monjo et al., 2012). It is worth noting, however, that this tiny elevation is a very delicate structure placed in a shearing ridge. Thus, it is easily worn by mastication and that usually leads to underestimation of the real incidence. Judging by the state of preservation of the holotype of $N$. rafelinensis, it seems difficult-if not impossible-to ascertain whether this structure was really present or not in the young animal. Therefore, it should not be considered a trustworthy diagnostic character.

With respect to the cuspule and the lingual crest on the posterolingual basin of $p 4$, it is difficult to ascertain whether those of $N$. ponsi, $N$. aff. ponsi and $N$. hidalgo are more conspicuous than in $N$. rafelinensis without comparing directly with the original material. Actually, only Reumer commented on this trait, specifying that "At the lingual side [i.e., of the p4] the basin is bordered by a small ridge running down from the protoconid" (Reumer, 1980, p. 55), but his figures do not provide further details. In our opinion, neither the classic works (Reumer, 1979, figures 3, 4, 1980, figure 11; Pons-Moyà and Moyà-Solà, 1980, figure 1), nor the recent one (Rofes et al., 2012, figure 3) have sufficient resolution to carry out a reliable comparison to elucidate which taxon's p4 has the most prominent lingual crests and cuspules. In Figure 2 we provide photographs of other specimens from $\mathrm{PO}$ and $\mathrm{CC}$ with the p4 showing no significant differences with the material from Caló d'en Rafelino. This trait is therefore not sufficient for future taxonomic identifications.

Pigmentation is described in the diagnosis of the species as "light orange at the top of the crowns." Nevertheless such coloration is not discernible in figure 3 of Rofes et al. (2012). Shadowed areas at the upper labial zones of the p4, m1 


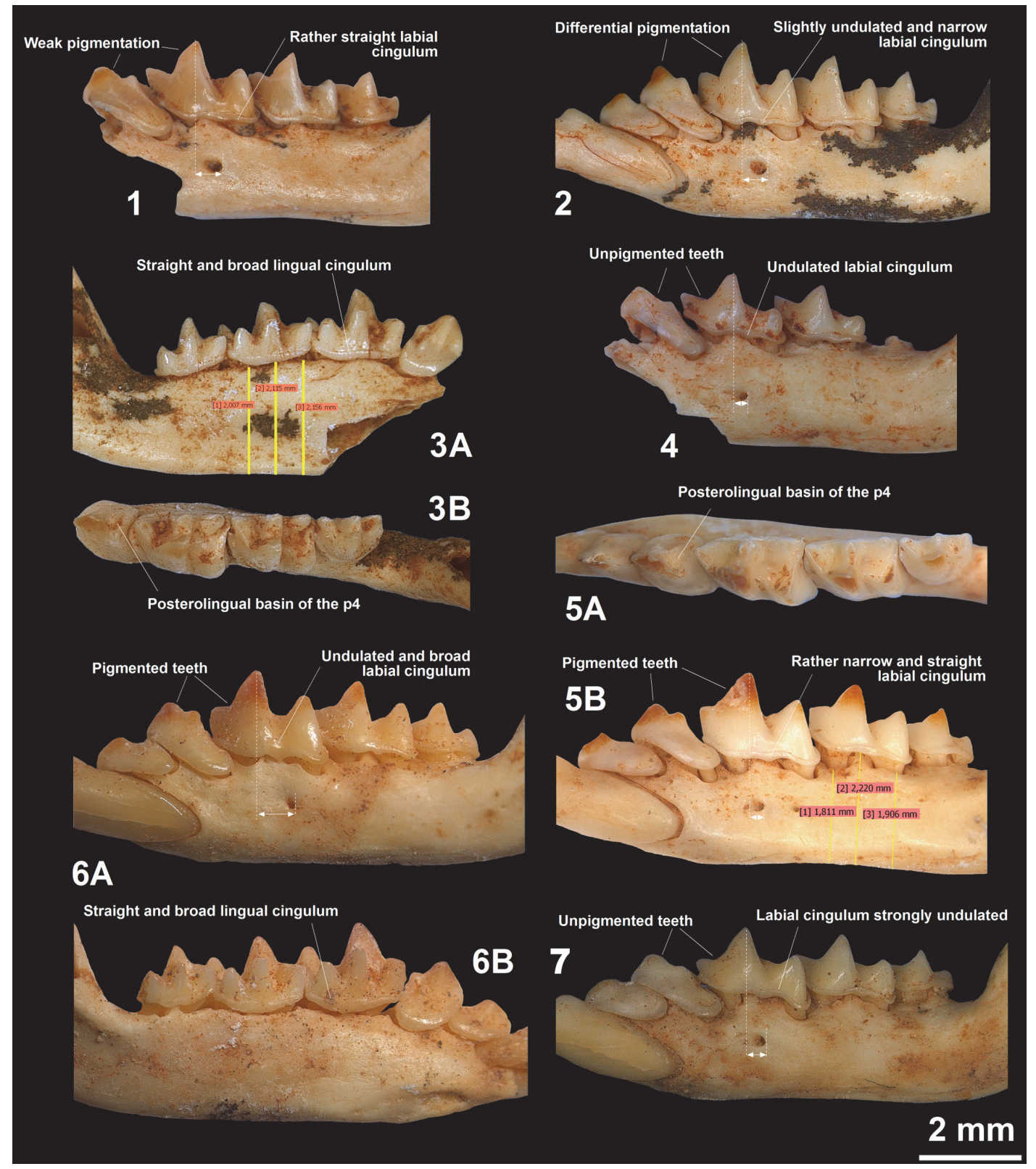

FIGURE 2. Left hemimandibles of Nesiotites aff. ponsi from PO (1-4) and N. hidalgo from CC (5-7) showing morphological variability by combination of different states on the considered diagnostic characters of $N$. rafelinensis. 1IPS51548; 2-IPS52318; 3-IPS52125 (A-Lingual view; B- Occlusal view); 4-IPS51469; 5-50483 (A- Occlusal view; BLabial view); 6-IPS50626 (A-Labial view; B-Lingual view); 7-IPS50482. Arrows indicate the distance from the posterior extreme of the mental foramen to the vertical line crossing the tip of the protoconid. Notice that in $3 \mathrm{~A}$ and $5 \mathrm{~B}$ (examples randomly selected), any of these possible ways of measuring $\mathrm{Hm} 2$ by the lingual or the labial side indicate a more robust mandibular body than that of the specimen from Calo d'en Rafelino. Occlusal (3B, 5A) and lingual views (3A, $6 \mathrm{~B}$ ) of $N$. aff. ponsi and $N$. hidalgo have been included to be compared with the holotype of " $N$. rafelinensis" (Rofes et al., 2012, figure 3). Notice that morphological differences between " $N$. rafelinensis" and $N$. aff. ponsi are minimal.

and $\mathrm{m} 2$ enamel are the only likely indications of a possible residual pigmentation. Moreover, the description states that "all dental elements are supposed to be stained (...). However, only a trace of the pigment remains at the very top of the crowns
(...), probably due to taphonomical reasons" (Rofes et al., 2012, p. 6). After the thorough study of our thousands of specimens from BB, PO and $\mathrm{CC}$, we found that the teeth of all Balearic Nesiotites are usually weakly pigmented (Figure 2.1) or 
they even look completely white to the naked eye (Figure 2.4, 2.7). Thus, the scarce pigmentation in the holotype of $N$. rafelinensis is probably not a taphonomical artifact, but a real biological character. Pigmentation is, for instance, a variable character in the ancestral subfamily Crocidorosicinae (Furió et al., 2007). According to Dannelid (1998), some soricine genera like Anourosorex, Chimarrogale and Nectogale have secondary unpigmented teeth, but in the latter two tooth pigmentation is visible under UV light. Not by chance, these two genera and Nesiotites belong to the same tribe, the Nectogalini (sensu Hutterer, 2005). To sum up, the light pigmentation of $N$. rafelinensis is not different to that of other specimens of Nesiotites from younger localities.

The fourth and the fifth diagnostic characters of $N$. rafelinensis relate to the cingulids of the lower teeth. Cingula are rather plastic structures, and their development is possibly functional and related to the reduction of strain during mastication (Anderson et al., 2011). After detailed inspection of our samples, we can point out several observations about these structural elements. First, the p4 usually displays a broad and well-defined curved cingulid (Figure 2), not different to that of $N$. rafelinensis. Second, lingual cingulids of the lower molars in all our specimens tend to be (when discernible) rather straight and broad, as in the holotype of this new species (Figure 2). Third, the labial cingulid of the $\mathrm{m} 1$ is usually thin and undulated in all the previously known Balearic Nesiotites spp., as correctly noticed by Rofes et al. (2012) different to the condition of $N$. rafelinensis. We could assess, however, some exceptions to this general rule in our specimens from $\mathrm{PO}$ and $\mathrm{CC}$, in which the labial cingulid varies considerably from rather straight (Figure 2.1 ) to very undulated (Figure 2.7), and from quite broad (Figure 2.6A) to very narrow (Figure 2.5B). In any case, this infrequent morphology of the labial cingulid of $\mathrm{m} 1$ in the specimen IMEDEA 91950 has been well observed by Rofes et al. (2012), and indeed it could be the only trait that differentiates this specimen from the rest of the other known Nesiotites from the Balearic Islands. If Asoriculus is accepted as the ancestor of Nesiotites, a straight and broad labial cingulid in $\mathrm{m} 1$ is probably a plesiomorphic character inherited from the former genus. The morphology of the labial cingulid of the $\mathrm{m} 1$ in Asoriculus (as 'Episoriculus') is clearly depicted in Reumer (1984, plates 28-31).

The last differential character is the position of the mental foramen. In our samples, this trait is somewhat erratic. For instance, in $\mathrm{PO}$ samples the position of the mental foramen varies from almost below the protoconid (Figure 2.4) to below the posterior part of the reentrant valley of the $\mathrm{m} 1$ (Figure 2.6A). Of course this is not a long distance in absolute terms, but these two extreme positions define a wide range in which the specimen IMEDEA 91950 shows one of the two extreme conditions. Moreover, as described in Pons-Monjo et al. (2012), some specimens display a double mental foramen, thus adding further variability within the Balearic populations.

For all the reasons exposed above, we think the morphological features of the specimen from Caló d'en Rafelino are not strong enough to differentiate it from $N$. ponsi. The morphological variation observed in the younger monospecific populations of Nesiotites (Table 1) should preclude the definition of a new species based on a single specimen which absolutely falls within the variability range of a previously known species. Prudence should be even higher if the Caló d'en Rafelino fossils are relatively early in their post-Messinian isolation. This is because the initial insular populations of Nesiotites would be expectedly less morphologically constrained than later ones, and variation would be probably larger. Usually, mammals isolated in islands present in general a large intraspecific variation (van der Geer et al., 2010). This effect has been reported in the insular deer from Gargano Hoplitomeryx, which experienced an adaptive intraspecific radiation with several contemporaneous ecomorphs coexisting (van der Geer, 2008). According to this author, the main driving force is the urge to occupy new ecological niches due to intraspecific competition. In the end, the larger variation of endemic insular mammals compared to their mainland relatives and the strong endemism usually obscures taxonomy (van der Geer et al., 2006).

Therefore, in the absence of further support for the definition of a new species, it seems more advisable to refer this specimen of Nesiotites from Caló d'en Rafelino to $N$. ponsi, or $N$. aff. ponsi if the authors think that the buccal cingulid of the $\mathrm{m} 1$ is a trait sufficiently important to consider it as a distinct (but related) form. Another option is to refer to this specimen as $N$. cf. ponsi, a better solution for those who might think that there are not sufficient traits to distinguish it at the species level, and specimen IMEDEA 91950 must be compared with $N$. ponsi.

\section{ACKNOWLEDGEMENTS}

This paper has been possible thanks to the support by the AGAUR of the Generalitat de Cata- 
TABLE 1. Compared values of lower dental measures in PO, BB and CC. Shadowed files correspond to measurements taken when sample was limited to 25 elements (Pons-Monjo et al., 2012), independently whether left or right, 'in situ' (i.e., in mandible) or not (i.e., loose). White files correspond to the new measurements taken on all measurable left hemimandibles with molar elements 'in situ' from each locality considered. Abbreviations: Ma: mandible; L: length; Lm1-m3: length of the lower molar row; Max: maximum; Min: minimum; N: number of specimens; Par: parameter; SD: standard deviation; TAW: talonid width; TRW: trigonid width; W: width.

PO BB CC

\begin{tabular}{|c|c|c|c|c|c|c|c|c|c|c|c|c|c|c|c|c|}
\hline & ar. & lin. & $n$ & . & D & $\mathbf{N}$ & n. & $n$ & x. & D & $\mathbf{N}$ & n. & Mean & x. & D & $\mathbf{N}$ \\
\hline \multirow[t]{6}{*}{ m1 } & 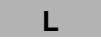 & & & & & 5 & & & & & 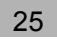 & & & & & 5 \\
\hline & L & & & & & & & & & & & & & & 07 & 65 \\
\hline & TAV & & & & & 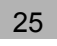 & & & & & & & & & & 5 \\
\hline & TAW & 114 & 120 & 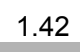 & & 3 & & & & & & & & & & 65 \\
\hline & TRW & & & & & & & & & & & & & & & 25 \\
\hline & TRV & 10 & & 1.01 & .05 & 93 & & & 1.22 & 0.00 & & & & & 0.0 & 65 \\
\hline \multirow[t]{6}{*}{$\mathbf{m}$} & L & & 1.8 & 1.96 & 0.07 & 25 & 1.75 & & 1.95 & 0.06 & 25 & & & & 0.07 & 25 \\
\hline & $\mathbf{L}$ & 00 & 1.75 & 1.94 & 0.07 & 93 & & 1.8 & 1.92 & 0.07 & & 183 & & 218 & 0.07 & 65 \\
\hline & TAV & 1.0 & 1.1 & 1.1 & 0.04 & 25 & & & 1.25 & 0.06 & 25 & & & & 4 & 25 \\
\hline & TAW & 0 & 1.1 & 1.2 & 0.06 & 93 & 1.0 & 1.1 & 1.30 & 0.08 & 5 & 11 & 1 & 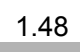 & 0.07 & 65 \\
\hline & & & & 1.15 & & 25 & & & 1.23 & & 25 & & & & & 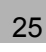 \\
\hline & TF & & & & & 93 & & & 20 & .00 & & & & & & 65 \\
\hline \multirow[t]{4}{*}{$\mathbf{m}$} & - & 8 & 1.36 & 1.45 & 0.06 & 25 & ? & 1.4 & 1.55 & 0.05 & 21 & 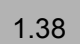 & 1. & 17 & - & 25 \\
\hline & L & & & 1. & & 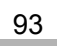 & & & & & 7 & & & & & 65 \\
\hline & 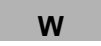 & & & & & $2 v$ & & & & & 21 & & & & & 25 \\
\hline & $\mathbf{w}$ & .76 & 0.89 & 1.02 & 0.05 & 93 & & & 0.95 & & 7 & & & 1.19 & 0.07 & 65 \\
\hline \multirow[t]{2}{*}{$\mathrm{Ma}$} & & & 4.96 & 5.09 & & 25 & & & & & 7 & & & 5.64 & 0.12 & 25 \\
\hline & Lm1-3 & 42 & 4.88 & 5.15 & 0.13 & 93 & 4.95 & 5.08 & 5.28 & 0.11 & 7 & 5.00 & 5.32 & 5.70 & 0.12 & 65 \\
\hline
\end{tabular}

lunya (PIPH- 2009 SGR 754) and the Spanish Ministerio de Economía y Competitividad (Project CGL2011-28681). We appreciate the helpful comments of two authors of the original paper and two anonymous reviewers, and the suggestions of $\mathrm{R}$. Minwer-Barakat (ICP) and L.W. van den Hoek Ostende (N.C.B. Naturalis). We acknowledge Z. Cofran (Nazarbayev University), who improved the English expression of the manuscript. M. Köhler, S. Moyà-Solà and X. Jordana (ICP) helped us recommending specific references on insular evolution.

\section{REFERENCES}

Anderson, P.S.L., Gill, P.G., and Rayfield, E.J. 2011. Modeling the Effects of Cingula Structure on Strain Patterns and Potential Fracture in Tooth Enamel. Journal of Morphology, 272:50-65.

Dannelid, E. 1998. Dental adaptations in shrews, p. 157174. In Wojik, J.M. and Wolsan, M. (eds.), Evolution of Shrews. Mammal Research Institute, Polish Academy of Science, Bialowieza.

Furió, M., Santos-Cubedo, A., Minwer-Barakat, R., and Agustí, J. 2007. Evolutionary history of the African soricid Myosorex (Insectivora, Mammalia) out of Africa. Journal of Vertebrate Paleontology, 27:10181032.
Hammer, Ø., Harper, D.A.T., and Ryan, P.D. 2001. PAST: Paleontological statistics software package for education and data analysis. Palaeontologia Electronica, 4(1):9 pp. palaeo-electronica.org/2001_1/past/issue1_01.htm

Hutterer, R. 2005. Order Soricomorpha, p. 220-311. In Wilson, D.E. and Reeder, D.M. (eds.), Mammal Species of the World. A Taxonomic and Geographic Reference, third edition, Volume 1. The Johns Hopkins University Press, Baltimore, Maryland.

Pons-Moyà, J. and Moyà-Solà, S. 1980. Nuevo representante del género Nesiotites Bate, 1944; Nesiotites meloussae nov. sp. (Insectivora, Soricidae) de los rellenos cársticos del Barranc de Binigaus (Es Mercadal, Menorca). Endins, 7:53-56.

Pons-Monjo, G., Moyà-Solà, S., and Furió, M. 2012. New data on the origin of Nesiotites (Soricidae, Mammalia) in Menorca (Balearic Islands, Spain). Comptes Rendus Palevol, 11:393-401. dx.doi.org/10.1016/ j.crpv.2012.03.001

Reumer, J.W.F. 1979. On two new micromammals from the Pleistocene of Mallorca. Proceedings of the Koninklijke Nederlandse Akademie van Wetenschappen, 82:473-482. 
Reumer, J.W.F. 1980. On the Pleistocene shrew Nesiotites hidalgo Bate, 1944 from Majorca (Soricidae, Insectivora). Proceedings of the Koninklijke Nederlandse Akademie van Wetenschappen, 83:38-68.

Reumer, J.W.F. 1984. Ruscinian and early Pleistocene Soricidae (Insectivora, Mammalia) from Tegelen (The Netherlands) and Hungary. Scripta Geologica, 73:1173.

Rofes, J., Bover, P., Cuenca-Bescós, G., and Alcover, J.A. 2012. Nesiotites rafelinensis sp. nov., the earliest shrew (Mammalia, Soricidae) from the Balearic Islands, Spain. Palaeontologia Electronica 15(1), $8 A: 12 p$. van der Geer, A. 2008. The effect of insularity on the Eastern Mediterranean early cervoid Hoplitomeryx: the study of the forelimb. Quaternary International, 182(1):145-159.

van der Geer, A., Dermitzakis, M., and de Vos, J. 2006. Crete before the Cretans. The reign of dwarfs. Pharos, 13:121-132.

van der Geer, A., Lyras, G., de Vos, J., and Dermitzakis, M. 2010. Evolution of Island Mammals. Wiley-Blackwell, Oxford, $496 \mathrm{p}$. 